\title{
Characteristics of patients with Alzheimer disease responders to treatment with cholinesterase inhibitors: a review in a country southern reference center
}

\begin{abstract}
Objective: To draw a physiological and behavioral profile from patients treated at Policlínica established in the city of Londrina in order to identify the developments caused by the use of Anticholinesterasics and also to evaluate the main characteristics of those patients.

Method: Cohort retrospective, through the collection and analysis of data obtained from medical records from 39 patients who fulfilled all the necessary criteria.

Results: The average age of patients was 76,6 years, the majority being female $(73,3 \%)$ and illiterate $(63,2 \%)$. The majority did not present comorbidities such as stroke $(89,5 \%)$ and traumatic Brain Injury (TBI) $(97,4 \%)$, although $60,5 \%$ have some cardiovascular disease associated. The Basic Activity of Daily living (ADLs) from 81 , $6 \%$ of the patients did not change between the current one and the one found at the diagnosis time. The Mini Mental State Examination (MMSE) had its value unchanged in $21,1 \%$ of the patients and had its high value at 1 point in $10,5 \%, 2$ points in $21,1 \%$ and in 3 or more points in $13,2 \%$ of the cases. There was a decrease of the MMSE value in 1 point in $7,9 \%$ of the patients, 2 points in $10,5 \%$ and 3 or more points in $6 \%$. Among the medicine used, Donepezil was the most prevalent one $(73,6 \%)$, followed by Galantamine $(15,8 \%)$ and by Rivastigmine $(10,5 \%)$. Besides, the Memantine was associated to Donepezil in 2 cases and to Galantamine in 1 case.
\end{abstract}

Conclusion: The results showed a correlation between Basics ADLs and TBI variables; educational level and MMSE variation and family history of AD and cardiovascular disease. The other risk and protective factors studied were not determinant for the outcome of the disease probably due to its multifactorial characteristic.

Keywords: Alzheimer's disease, cholinesterase inhibitors, mental, clinical features, protein, microtubule, anticholinesterase, human, females, cardiovascular disease, family history, rivastigmine
Volume 2 Issue 4 - 2018

\author{
Denise Camilios Cossiolo, Aline Garcia \\ Ferrari, Cristiane França da Silva, Jhayanne \\ Brunna de Costa, Lindsey Mitie Nakakogue \\ Department of Alzheimer disease, Pontifícia Universidade \\ Católica do Paraná, Brazil
}

Correspondence: Denise Camilios Cossiolo, Department of Alzheimer disease, Pontifícia Universidade Católica do Paraná, Londrina , Brazil, Email deniseccossiolo@gmail.com

Received: July 19, 2018 | Published: August 01, 2018

\section{Introduction}

Population aging has led to an increase in the prevalence of diseases related to senescence. ${ }^{1}$ Among them Alzheimer's disease (AD) stands out as one of the most relevant causes of dementia syndrome. Its first description occurred in 1906 by German physician Alois Alzheimer who reported clinical features and pathological manifestations of dementia in a 51-year-old woman. ${ }^{2}$ Currently, Alzheimer's Disease (AD) is defined as a progressive and fatal neurodegenerative disorder, which is manifested by cognitive and memory loss, progressive impairment of daily life activities and a variety of neuropsychiatric symptoms and behavioral changes. ${ }^{3}$ The main alterations observed in the pathophysiology of $\mathrm{AD}$ consist of high levels of $\beta$-amyloid peptide, deposited extracellularly in diffuse and neuritic plaques and hyperphosphorylated TAU protein, a microtubule accumulated in the intracellular medium as neurofibrillary tangles. ${ }^{4}$ In view of this situation, the use of anticholinesterase inhibitors, also called acetylcholinesterase (AChE) competition inhibitors, is essential to increase central cholinergic activity, even in the presence of decreased acetylcholine production (ACh) in patients with $\mathrm{AD}$. In addition, it enables both the increase of the endogenous ACh concentration released in the synaptic cleft and the activation and action of the adjacent cholinergic receptors, thus retarding the cognitive degradation of these patients. ${ }^{18-21}$ Therefore, the objective of this study is to outline a physiological and behavioral profile of patients followed at an Alzheimer's referral center in southern Brazil, in order to identify the consequences of anticholinesterase use and to evaluate the predominant characteristics of these patients, comparing these findings with the available literature.

\section{Methods}

This study was approved by the Research Ethics Committee of PUCPR, CAE 57289716.9.0000.0100. It was also granted authorization of data collection by the Department of Health of Londrina city in Paraná, Brazil. The respective study is a retrospective cohort study of patients attended at the Vila da Saúde in the city of Londrina, which provides care through the public Unified Health System and is considered a reference center for several clinical specialties. After deepening the knowledge on the subject through related 
bibliographical research, periodic meetings were held to discuss the bibliographic findings and focus on the main points analyzed during the evolution of the project. Previously, it was analyzed that 522 patients were attended at the Reference Service in Geriatrics in the year 2015. The selection of the target population was based on nonprobabilistic sampling by convenience method and included patients that met the prerequisites established by the present study. Patients with an established diagnosis of $\mathrm{AD}$ using cholinesterase inhibitor were therefore included after agreeing to participate in the study. Exclusion criteria were: patients with other comorbidities other than Alzheimer's disease; patients who discontinued treatment with AChE; patients with Mental State Mini Examination (MMSE) values greater than 10; patients who did not present in their medical records at least two MMSE or that presented in this score a drop of more than 2 points in MMSE in one year. Therefore, the sample population was reduced to 98 patients with diagnosed Alzheimer's disease and, subsequently, to 38 patients who met the inclusion criteria already mentioned. Data collection was carried out from July to October 2016, based on a questionnaire prepared by the authors. All selected patients were informed about the objectives and procedures to be performed and signed the Informed Consent Term. The collection of data respected the ethical aspects supported by Resolution 196/96 established by the National Health Council and was based on the ethical norms involving the research with human beings. These data were obtained from analyzed charts.

\section{Statistical analysis}

Data systematization and storage were performed from a standard database developed in the Microsoft Excel ${ }^{\circledR}$ program. Afterwards, the data were tabulated in the Statistical Package for the Social Sciences (SPSS), Windows Operating System, and version 12.0. In use for statistical analysis and generation of results from these data. The quantitative variables were described by mean and standard deviation and the categorical variables were verified and analyzed from absolute and relative frequencies. The technique used for the correlation of the data was Spearman's and the value of $p<0.05$ was considered statistically significant.

\section{Results}

The importance of treatment with medications capable of maintaining effective cholinergic activity and thus slowing the progression of $\mathrm{AD}$ has attracted increasing attention from the medical community. However, there is still a need to understand the characteristics related to Anticholinesterase users responding to treatment to outline a general parameter about their condition. The study showed that in the population evaluated the mean age of the patients was 76.6 years, ranging from 60 to 89 years (Table 1). It was verified that the majority of the patients were females, 28 of them $(73.3 \%)$, and, of the sample population of 38 study patients, at least $27(71.1 \%)$ had a caregiver to assist them in the activities, whether they are the spouse, a son or a caregiver of these patients. The majority of the people studied declared themselves illiterate, 25(65.7\%), and of those attending school, $15.8 \%$ of them had an average school attendance of around 4 years of schooling, and only 4 of them (10.5 $\%$ ) has completed tertiary education. Regarding the possible relatable comorbidities, the vast majority of patients did not present events such as stroke, 34(89.5\%) and TBI, 37(97.4\%) in their previous history, although more than half of them, $21(55,3 \%)$, reported having some comorbidity associated with AD. Fifteen patients (39.5\%) reported suffering from depression on treatment, and 23(60.5\%) individuals reported having associated cardiovascular disease. As for their lifestyle habits, only one $(2.6 \%)$ of them confessed the habit of smoking. None of the patients evaluated claimed to be a chronic alcoholic, but 34(89.5) of them admitted to lack of regular physical activity. The majority denied the presence of a family history of $\mathrm{AD}$, $29(76.3 \%)$.

Table I Characteristics of the elderly with Alzheimer's disease

\begin{tabular}{|c|c|c|}
\hline Variables & $\mathbf{n}$ & $\%$ \\
\hline \multicolumn{3}{|l|}{ Age } \\
\hline 60-69 years old & 6 & 15,78 \\
\hline 70-79 years old & 15 & 39,47 \\
\hline $80-89$ years old & 17 & 44,75 \\
\hline \multicolumn{3}{|l|}{ Sex } \\
\hline Male & 10 & 26,3 \\
\hline Female & 28 & 73,7 \\
\hline \multicolumn{3}{|l|}{ Education } \\
\hline Illiterate & 25 & 65,7 \\
\hline Ist to $4^{\text {th }}$ grade 6 & & 15,8 \\
\hline $5^{\text {th }}$ to $8^{\text {th }}$ grade 3 & & 7,9 \\
\hline Full Higher Education & 4 & 10,5 \\
\hline \multicolumn{3}{|l|}{ Caregiver } \\
\hline Yes & 27 & 71,1 \\
\hline No & 11 & 28,9 \\
\hline \multicolumn{3}{|l|}{ Stroke } \\
\hline Yes & 4 & 10,5 \\
\hline No & 34 & 89,5 \\
\hline \multicolumn{3}{|l|}{ TBI } \\
\hline Yes & 1 & 2,6 \\
\hline No & 37 & 97,4 \\
\hline \multicolumn{3}{|l|}{ Smoking } \\
\hline Yes & 1 & 2,6 \\
\hline No & 37 & 97,4 \\
\hline \multicolumn{3}{|l|}{ Alcoholic } \\
\hline Yes & 0 & 0 \\
\hline No & 38 & 100 \\
\hline \multicolumn{3}{|l|}{ Family History } \\
\hline Yes & 9 & 23,7 \\
\hline No & 29 & 76,3 \\
\hline \multicolumn{3}{|l|}{ Physical Activity } \\
\hline Yes & 4 & 10,5 \\
\hline No & 34 & 89,5 \\
\hline ADLs & & \\
\hline
\end{tabular}

Citation: Cossiolo DC, Ferrari AG, Silva CF, et al. Characteristics of patients with Alzheimer disease responders to treatment with cholinesterase inhibitors: a review in a country southern reference center. Int J Fam Commun Med. 2018;2(4):207-2II. DOI: I0.15406/ijfcm.2018.02.0008I 
Table continued..

\begin{tabular}{|c|c|c|}
\hline Variables & $\mathbf{n}$ & $\%$ \\
\hline \multicolumn{3}{|c|}{ (In the diagnosis) } \\
\hline 6-Jun & 35 & 92,1 \\
\hline 6-May & 2 & 5,3 \\
\hline 6-Feb & 1 & 2,6 \\
\hline \multicolumn{3}{|c|}{ ADLs (Current) } \\
\hline 6-Jun & 31 & $8 I, 6$ \\
\hline 6-May & 4 & 10,5 \\
\hline 6-Apr & I & 2,6 \\
\hline 6-Mar & I & 2,6 \\
\hline 6-Feb & I & 2,6 \\
\hline \multicolumn{3}{|l|}{ Depression } \\
\hline Yes & 15 & 39,5 \\
\hline No & 23 & 60,5 \\
\hline \multicolumn{3}{|c|}{ Cardiovascular disease } \\
\hline Yes & 23 & 60,5 \\
\hline No & 15 & 39,5 \\
\hline \multicolumn{3}{|c|}{ Comorbidities } \\
\hline Yes & 21 & 55,3 \\
\hline No & 17 & 44,7 \\
\hline \multicolumn{3}{|l|}{ Vit B I 2} \\
\hline Yes & 3 & 7,9 \\
\hline No & 35 & 92,1 \\
\hline \multicolumn{3}{|c|}{ Anticholinesteric } \\
\hline Rivastigmine & 4 & 10,5 \\
\hline Donepezil & 27 & 71,05 \\
\hline Galantamine & 7 & 18,45 \\
\hline Memantine & 3 & 7,89 \\
\hline
\end{tabular}

One of the methods of geriatric evaluation is based on the ADLs analysis. Statistical analysis indicated that $81.6 \%$ did not present any alteration in their current ADLs (6/6) compared to the ADLs established at diagnosis. This decline occurred in only $18.3 \%$ of cases. Regarding the MMSE alteration, eight $(21.1 \%)$ of them maintained the same value, and the rest of these patients (30 of them) showed some alteration. Of those people evaluated, 17 had a significant improvement, increasing the MMSE score by respectively 1 point $(10.5 \%), 2$ points $(21.1 \%)$ and 3 or more points $(13.2 \%)$. However, $34.2 \%$ of the patients showed a decline in the MMSE score. Three of them $(7.9 \%)$ had a one-point worsening, $4(10.5 \%)$ of them fell 2 points and the remaining 6 declined significant 3 points or more. Regarding pharmacological measures, the majority of the patients analyzed did not use vitamin B12, $35(92.1 \%)$ in the therapeutic course, but all used some type of anticholinesterase inhibitor. The most prevalent anticholinesterases were Donepezil in $73.6 \%$ (28 patients) of the cases, followed by Galantamine ( $15.8 \%-6$ cases) and Rivastigmine (10.5\% -4). In 3 cases, Memantine, a noncompetitive antagonist of NMDA glutamate receptors also used in the treatment of $\mathrm{AD}$, was associated with treatment with both Donepezil (in 2 cases) and Galantamine (1 case).

\section{Discussion}

In relation to sex, $73.7 \%$ of the patients analyzed were female. However, there was no correlation between the female sex and higher incidence of Alzheimer's, or between female sex and performance in the MMSE. This is in agreement with some already published studies analyzed that did not show significantly lower rates of $\mathrm{AD}$ in men compared to the women present in the studied group. However, other publications have stated that female sex is a risk factor for the disease, thus presenting differences in the literature. ${ }^{1-6}$ As for the smoking variable, previous data have already indicated it as a protective factor for the development of Alzheimer's, attributing this protection to some neurophysiological mechanism of nicotine. ${ }^{7,8}$ However, later studies have found that smokers die earlier. Also, more recent research indicates that there is a greater risk of developing Alzheimer's and other mental illnesses in smokers. ${ }^{9,10}$ In this study, $97.4 \%$ of the patients were not smokers, but this data was not relevant when compared to the incidence of AD and MMSE. Publish studies point to excessive alcohol consumption as responsible for a more accelerated cognitive decline in Alzheimer's disease, being responsible for altering the course of the disease. ${ }^{11}$ However, there are researches that relate moderate consumption of beverages such as wine to protection against neurodegenerative diseases due to their antioxidant properties, the effects against $A \beta$ amyloid and the prevention of alcohol-related ischemia or stroke. ${ }^{6}$ In our study, $100 \%$ of the patients were nonalcoholic, and this did not show a significant correlation with the incidence of AD.

In this study, $60.5 \%$ presented cardiovascular disease, a factor that was directly proportional to the family history of Alzheimer's disease (Spearman's test, $\mathrm{R} 2=0.333, \mathrm{P}=0.048$ ). The association between cardiovascular disease and $\mathrm{AD}$ is described in the literature, pointing to cardiovascular diseases as one of the risk factors for Alzheimer's development. ${ }^{6}$ Researches associate diseases such as atherosclerosis, hypertension and vascular rigidity with increased accumulation of beta-amyloid plaques. Adequate treatment of these diseases can prevent or delay the exaggerated deposition of plaques. ${ }^{13}$ Other studies also point out that an isolated cardiovascular disease is not a proven risk factor for $\mathrm{AD}$, and an association of diseases is necessary for the development of Alzheimer's disease. ${ }^{14}$ In the statistical analysis already mentioned, it was verified that there is a correlation between Stroke and age (Spearman's test, R2 $=-0.004$ ), because the greater the patient's age, the grater the probability of stroke, data that comes from literature. This means that the risk of this disease increases at advanced ages. ${ }^{15}$ According to a study by Honig (2003), stroke is strongly associated with Alzheimer's disease in the elderly, being an important risk factor for AD. ${ }^{16}$ Regarding the degree of dependency of the elderly analyzed, the Katz Scale (ADLs) was considered, which allows to evaluate the autonomy of these patients for their basic activities. This scale evaluates and classifies the patient from independent to totally dependent. ${ }^{17}$

There are reports that patients with AD present ADLs damage only in the advanced stages of the disease, since they suffer progressive loss due to cognitive impairment in the disease progression. ${ }^{18}$ In this study, ADLs was analyzed in the diagnosis and during the evolution of the patients, and in the two variables, the majority presented a result that shows independence. However, this number was higher in ADLs at diagnosis. Maintaining independence indicates treatment effectiveness. The analysis of patients previous histories show that some elderly people who have developed Alzheimer's have in common 
the fact that they had suffered TBI before diagnosis. ${ }^{19}$ This correlation between TBI and AD was confirmed in this study, as the statistical analysis detailed a strong correlation between patients with a history of TBI with low ADLs in the diagnosis of the disease (Spearman's test, $\mathrm{R} 2=-0.593, \mathrm{P}<0.01$ ). This connection was expected because trauma associates and corroborates with the pathophysiological changes of the disease, with a greater chance of loss of the elderly's functionality, making them more vulnerable to falls, injuries, fractures, vestibular alterations and gait disturbances. ${ }^{18-20}$ Studies have shown that about $60 \%$ of patients with cognitive decline suffer twice as many falls and fractures, thus being more likely to have TBI. ${ }^{18}$ Acetylcholinesterase inhibitors $(\mathrm{AChEi})$, the drugs of choice in the treatment of $\mathrm{AD}$, have the effect of competition inhibition of Acetylcholinesterase (AChE) and increase the concentration of endogenous ACh released in the synaptic cleft, potentiating the activation and action of the adjacent cholinergic receptors ${ }^{(21)}$. Thus, the therapeutic use of AChEi has as mechanism the increase of the central cholinergic activity even in view of the little production of neurotransmitter caused by the disease. Currently in Brazil, the most used AChEi are the second generation, reversible, known as Rivastigmine, Galantamine and Donepezil. ${ }^{18}$

Rivastigmine is an AChEi that affects both $\mathrm{AChE}$ and BuChE (butyrylcholinesterase) enzymes, temporarily inhibiting them. This mechanism makes it more suitable for patients in more advanced stages of the disease, establishing as dosage two doses per day, in the morning and at night, orally. ${ }^{21-23}$ Galantamine, on the other hand, acts as an allosteric potentiating ligand of nicotinic receptors. ${ }^{21}$ It is administered in a daily dosage, ranging from 8 to $24 \mathrm{mg} / \mathrm{dose}$. Donepezil is given as a single daily dose, preferably in the evening, with a dosage of 5 to $10 \mathrm{mg} /$ day. ${ }^{23}$ All patients selected were using AChE during data collection: $4(10.5 \%)$ of them took Rivastigmine, $6(15.7 \%)$ were treated with Galantamine and the rest, $28(73.6 \%)$, used Donepezil as the drug of choice. Six (15.7\%) of them still had AChE1 associated with Memantine, a non-competitive antagonist of moderate affinity for glutamate NMDA receptors, which, by reducing ACh-related neural excitotoxicity, also acts in the treatment of cognitive disorders and behavioral symptoms of dementia. ${ }^{22}$ Statistical data also showed no difference in efficacy among the AChEi used, since for all the drugs studied there was presence of both the clinical improvement pattern and the decrease in the MMSE score. This probably demonstrates that the medication used helps to maintain the current MMSE, although other related and already discussed factors also influence the evolution of the condition described here. There was also no significant improvement in MMSE or ADLs performance in patients who had used the AChEi associated with Memantine. Regarding the use of vitamin B12, it is known that its deficit is an important differential diagnosis with $\mathrm{AD}$, since it is related to neurological and biochemical alterations that increase the risk of disease development. ${ }^{1-24}$ However, concomitant administration of vitamin B12 and AChEi in subjects who confirmed their use did not alter their performance in ADLs or in the MMSE.

\section{Conclusion}

This research was delineated from a specific population of a reference center, and therefore not generalizable, especially with regard to study design and sample size. Nevertheless, the study revealed an inversely proportional correlation between the ADLs and the presence of TBI and between the level of schooling and the MMSE variation. Also demonstrates a directly proportional correlation between family history of Alzheimer's disease and cardiovascular disease. Although there are risk and protection factors, in our research they were not significant to determine the outcome of Alzheimer's disease, due to the multifactorial characteristic of AD.

\section{Acknowledgements}

None.

\section{Conflict of interest}

The author declares there is no conflict of interest.

\section{References}

1. Aprahamian I, Martinelli JE, Yassuda MS. Doença de Alzheimer: revisão da epidemiologia e diagnóstico. Rev Bras Clin Med. 2009;7:27-35.

2. Rowland LP, Pedley TA, Merritt. Tratado de Neurologia. Rio de Janeiro: 7th edition. Guanabara Koogan; 2007. p. 36.

3. Brasil. Ministério da Saúde. Biblioteca Virtual em Saúde. Portaria No 491 de 23 de Setembro de 2010. Brasília: MINISTÉRIO DA SAÚDE; 2010.

4. Reitz C, Braine C, Mayeux R. Epidemiology of Alzheimer disease. Nature Reviews Neurol. 2008;7(3):137-152.

5. Katz, Mindy J, Hall CB, et al. Age-specific and Sex-specific Prevalence and Incidence of Mild Cognitive Impairment, Dementia, and Alzheimer Dementia in Blacks and Whites. Alzheimer Dis Assoc Disord. 2012;26(4):335-343.

6. Teixeira JB, Souza-Junior PRB, Higa J, et al. Mortality from Alzheimer's disease in Brazil, 2000-2009. Cadernos de Saúde Pública. 2015;31(4):850-860.

7. Vandujin CM, Clayton DG, Chandra V, et al. Interaction between genetic and environmental risk factors for Alzheimer's disease: a reanalysis of case-control studies. Genetics Epidemiology. 1994;11(6):539-551.

8. Newhouse PA, Potter A, Levin ED. Nicotinic system involvement in Alzheimer's and Parkinson's disease. Drugs and Ageing. 1997; 11(3):206-228.

9. Riggs JE. Smoking and Alzheimer's disease: protective effect or differential survival bias? Lancet. 1993; 342(8874):793-794.

10. Malbergier A, Oliveira Junior HP. Dependência de tabaco e comorbidade psiquiátrica. Rev Psiquiatr Clín. 2005;32(5):276-282.

11. Heymann D, Stern Y, Cosentino S, et al. The Association between Alcohol Use and the Progression of Alzheimer's disease. Current Alzheimer Res. 2016;13(999):1-7.

12. Huang WJ, Zhang X, Chen WW. Association between alcohol and Alzheimer's disease. Exp Ther Med. 2016;12(3):1247-1250.

13. Claassen JA. New cardiovascular targets to prevent late onset Alzheimer disease. Eur J Pharmacol. 2015;763(Pt A):131-134.

14. Purnell C, Gao S, Callahan CM, et al. Cardiovascular Risk Factors and Incident Alzheimer Disease. Alzheimer Dis Assoc Disord. 2009;23(1):110 .

15. Azeredo Z, Matos E. Grau de dependência em doentes que sofrem AVC. RFML. 2003;8(4):199-204.

16. Correia A, Filipe J, Santos A, et al. Nutrição e Doença de Alzheimer. 1st edition. Portugal: Programa Nacional para Promoção da Alimentação Saudável; 2015.p. 1-78.

17. Apóstolo JLA. Instrumentos para avaliação em geriatria. Esenfc maio. 2012. 
18. Zidan M, Arcoverde C, Araújo NB, et al. Alterações motoras e funcionais em diferentes estágios da doença de Alzheimer. Rev Psiq Clín. 2012;39(5):161-165.

19. Barranco-Quintana JL, Allam MF, Del Castillo AS, et al. Risk factors for Alzheimer's disease. Rev Neurol. 2005;40(10):613-618.

20. Barreto TLD, Sousa TMN, Barbosa R.B, et al. A doença de Alzheimer e seus efeitos fisiológicos no organismo. Anais CIEH. 2015;2(1).

21. Golan DE, Tashjian Junior AH, et al. Princípios de Farmacologia: A base fisiopatológica da farmacoterapia. 3rd edition. São Paulo: Guanabara Koogan; 2009.
22. Vale FAC, Neto YC, Bertolucci PHF, et al. Tratamento da doença de Alzheimer. Dement Neuropsychol. 2011;5(1):34-48.

23. Engelhardt E, Brucki SMT, Cavalcanti JLS, et al. Tratamento da doença de Alzheimer. Arq Neuropsiquiatr. 2005;63(4):1104-1112.

24. Futterleib A, Cherubini K. Importância da vitamina B12 na avaliação clínica do paciente idoso. Scientia Medica. 2005;15(1):74-88. 